DOI: 10.20472/IAC.2018.039.009

\author{
ARIADNA CIAZZŻELA \\ The Maria Grzegorzewska University, Poland
}

\title{
WILL HUMAN INGENUITY PREVENT THE EARTH FROM BECOMING UNLIVABLE? YOUNG POLES' BELIEFS ABOUT THE NATURAL ENVIRONMENT
}

\begin{abstract}
:
The aim of the presentation is to share results of a study concerning the beliefs about the natural environment conducted with the use of New Ecological Paradigm Scale (R. Dunlap et al.), which, according to the authors, is a measure of endorsement of a "pro-ecological" world view and environmental concern. Items in the questionnaire involve such topics as the reality of growth limits, anti-anthropocentrism, the fragility of nature's balance, rejection of exemptionalism, and the possibility of an ecological catastrophe. The NEP Scale was previously used in different countries, including USA, Mexico, Germany, Czech Republic, Turkey and Brazil. The presented research is one of few extensive studies using the NEP scale that have been pursued in Poland.

The study was conducted at various Warsaw universities and other academic centres across Poland in 2016. The results indicate that most participants believe that humans are seriously abusing the environment and the threat of a serious crisis is real. On the other hand, however, they are optimistic about the natural resources and hope that human ingenuity will prevent the disaster. Most participants show rather biocentric than anthropocentric beliefs, including such opinions as "plants and animals have as much right as humans to exist," or "humans don't have the right to modify the natural environment to suit their needs." The study was carried out as a part of a larger project, which aim was to examine the respondents' knowledge about the natural environment, their pro-ecological behaviour, and the correlation of the latter with the beliefs measured by the NEP scale.
\end{abstract}

\section{Keywords:}

New Ecological Paradigm Scale, natural environment, environmental attitudes, Poland, young Poles 